Article

\title{
Energy Demand Reduction in the Residential Building Sector: A Case Study of Korea
}

\author{
Kwon Sook Park ${ }^{1}$ (i) and Mi Jeong Kim ${ }^{2, *}$ \\ 1 Department of Architecture, Korea University, Seoul 02841, Korea; kiara1335@hotmail.com \\ 2 Department of Housing and Interior Design, Kyung Hee University, Seoul 02447, Korea \\ * Correspondence: mijeongkim@khu.ac.kr; Tel.: +82-2-961-9275
}

Received: 27 August 2017; Accepted: 25 September 2017; Published: 28 September 2017

\begin{abstract}
This study sought to examine ways of reducing energy demands in the residential building sector by measuring energy usage and associated factors in Bundang District. This District represents the first phase of new towns in the Seoul metropolitan region to implement current polices directed at climate change. The majority of residential buildings in this district were constructed between 1991 and 1995, prior to the announcement of the integrated building design criteria directed at saving energy and intensifying thermal transmittance. The proportion of small households was increased by almost $40 \%$ from 2000 to 2010 . Further, a number of weather records have been broken in the last two decades. These changes are strongly related to energy consumption patterns and trends; however, current polices, acts, and regulations do not sufficiently address these issues. This study suggests building energy-saving strategies that: (i) improve energy performance in existing buildings; (ii) strengthen building design criteria to address climate change issues, especially in relation to design and construction; and (iii) offer a framework to revitalize Korea's energy-savings policies.
\end{abstract}

Keywords: residential building; energy demand reduction; building deterioration; historical temperature trends; case study

\section{Introduction}

Korea's urbanization rate grew rapidly with compressed economic growth; however, this growth created serious social, economic, and environmental problems such as housing shortages, traffic congestion, environmental deterioration, and community collapse [1]. Further, it is inextricably tied to increased greenhouse gas emissions. Increased greenhouse gas emissions are mostly a result of excessive energy being used to improve living standards and climate change. Korea's surface temperature rose by $1.7^{\circ} \mathrm{C}$ to be far above the global average surface temperature from 1912 to 2008 . In a survey conducted by Korea's Ministry of Environment, 88\% of the 1040 adults questioned indicated that they were aware that burning fossil fuels had caused global warming and climate change. In this context, the Korean government declared its vision of 'Low Carbon, Green Growth' and, in 2008, set reduction targets that responded to increases in energy consumption and greenhouse gas emissions across all sectors (e.g., power, industrial processes, transportation, building, agriculture and fisheries, waste, and public other). According to the international energy agency [2], the world is confronted with similar problems in terms of climate change and greenhouse gas emissions; for example, the rise in the global mean temperature of $2{ }^{\circ} \mathrm{C}$ and the cost and difficulty of mitigating greenhouse gas emissions. Many countries have worked together and made efforts to solve the energy-related issues. The United States set a binding target to reduce its net greenhouse gas emissions to $28 \%$ in 2025-below the levels of 2005-and introduced energy and climate policies such as the Climate Action Plan and the Clean Power Plan, tax credits for wind and solar, and renewable portfolio standards. The European Union also set a target to reduce greenhouse gas emissions by at least $40 \%$ in 2030- to a level comparable with 
that of 1990-and to increase the share of renewable energy to at least $27 \%$ (of final energy consumption) based on their 2030 framework for energy and climate policies. Further, although China's ongoing economic and social development, in addition to climate change, demand the continued expansion of the energy sector, they have introduced more stringent fuel-economy standards and made efforts to increase the share of non-fossil fuels in primary energy consumption to around $20 \%$ by 2030 .

Following the transportation sector, the second highest target was set for the building sector (the second largest contributor to greenhouse gas emissions), as this sector can significantly reduce its energy consumption and greenhouse gas emissions if diverse efforts are made [3]. Despite the establishment and gradual strengthening of policies, it appears that the government may not achieve its target to reduce carbon dioxide emissions by $26.9 \%$ (i.e., approximately one quarter of the national target) below business-as-usual (BAU) levels by 2020 or meet its zero energy housing target by $2025[4,5]$. Presently, electricity use is rising faster than expected, the energy supply plan was disrupted due to a reduction in reliance on nuclear power (i.e., from $41 \%$ to $29 \%$ of the total primary energy supply), and the mandated target for new and renewable energy ( $11 \%$ of the total primary energy supply) has been delayed by five years (from 2030 to 2035). The efficiency of renewable energy generation is determined according to surrounding conditions. The system of renewable energy is not yet fully established and its cost is still quite high compared with that of other energies [6,7]. Recently, the Korean government started to limit the expansion of nuclear power by stopping the construction of nuclear power plants. However, the government has no concrete plans for the reduction of greenhouse gas emissions and for increasing alternative energy resources, such as renewable energy, and other currently unused but possible energy resources. To make concrete plans, the government needs to simulate energy performance in the design and operational stages, and the production of accurate data such as realistic occupancy profiles may also be essential [8,9].

This research sought to identify ways of reducing energy demand in the Korean building sector. Specifically, it analyzed energy consumption and associated factors such as social and environment changes and current policies directed at climate change. Further, to accurately capture the current state of the building sector, a case study was conducted on residential buildings with large floor areas that consume substantial amounts of electricity, gas, and district heating in the new town of Bundang. Greenhouse gas emissions in Korea are largely concentrated within the capital region. Data on the first phase of the new towns in the Seoul metropolitan region (e.g., Bundang, Sanbon, Jungdong, Pyeongchon, and Ilsan) have been collected and categorized based on the systematic development and energy demands of residential buildings. Data on Bundang was analyzed for this study, as the energy consumption statistics for the other new towns were not yet available.

\section{Energy Consumption in the Residential Building Sector: The Bundang District}

This section identifies the patterns of energy consumption in residential buildings in the Bundang district. Located in the Seoul metropolitan region, this area was developed in response to increases in housing prices and supply shortages in capital cities. The government's two million housing construction plan comprised various high-rise buildings, including luxury commercial-residential complexes and public rental housing.

\subsection{Energy Consumption and Sources}

Figure 1 sets out the total energy consumption (including electricity, gas, and district heating) and total carbon dioxide emissions for one year for residential buildings located in the Bundang District (data obtained from KEPCO (Korea Electric Power Corporation), KOGAS (Korea Gas Corporation), and KDHC (Korea District Heating Corporation)). Conditioned floor area (CFA) was used to determine gas and district heating consumption, and total upper floor areas were used to determine electricity consumption. Energy consumption was calculated in relation to the ton of oil equivalent (TOE) per unit of the land area. Compared to the energy consumption of commercial buildings, the increase of energy consumption in residential buildings occurred relatively slowly from 2005 to 2009. On average, 
approximately 250,000 TOE is consumed annually in residential buildings (comprising 549,409 MWh of electricity, $27,957 \mathrm{~km}^{3}$ of gas, and 107,604 $\mathrm{km}^{3}$ of district heating). According to the Korea Energy Economics Institute, in 2008, approximately $77 \%$ of the total energy consumption in residential buildings was used for space heating, water heating, and cooking (heating load), a decrease from $91 \%$ in 1990. The remaining 23\% was used for air conditioning, electronics, and lighting (electricity load). Space heating represents the largest percentage of energy consumption, but this figure declined from $66.4 \%$ to $44.2 \%$ between 1990 and 2008 due to energy efficiency improvements (e.g., district heating being supplied to nearly $100 \%$ of apartments, and public buildings in the Bundang district and $61.7 \%$ of district heating using space heating).

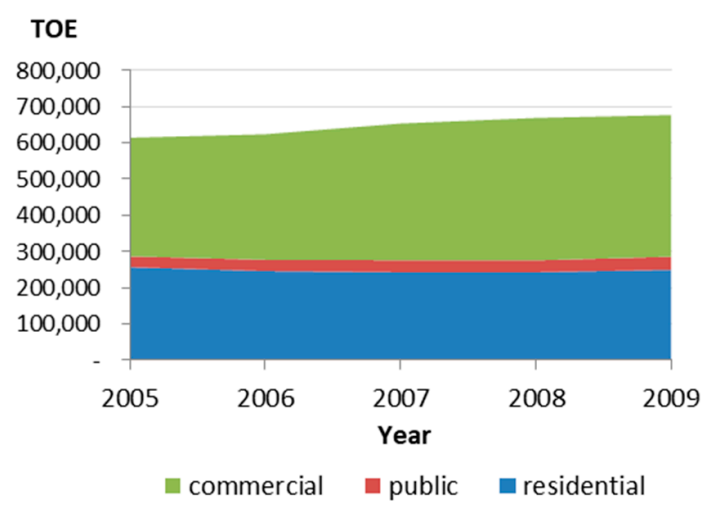

(a)

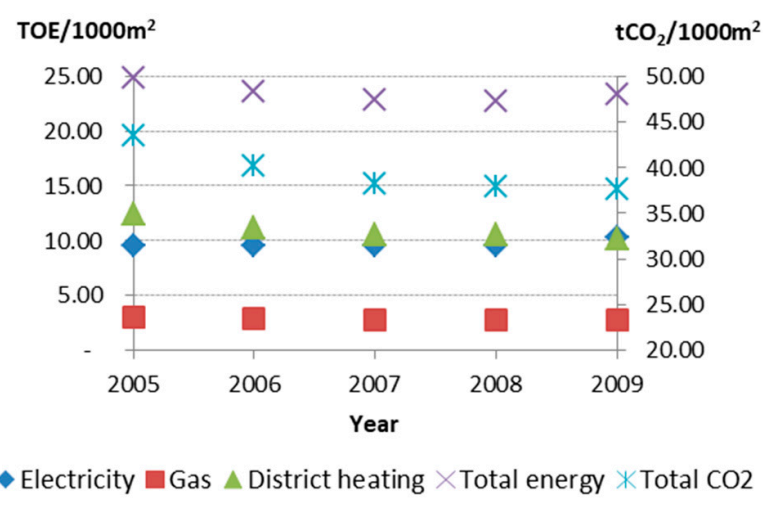

(b)

Figure 1. (a) Energy consumption in relation to building types; (b) energy sources in residential buildings.

\subsection{Energy Demands: Electricity, Gas, and District Heating}

Figures 2 and 3 show monthly electricity demands and growth and monthly gas and district heating demands, respectively. Presently, residential buildings account for approximately $37 \%$ of the total building energy being consumed in the Bundang district. This statistic has not changed significantly despite the fact that the energy consumption of commercial and public buildings may vary depending on government policies on issues such as the global environment and resource depletion. Residential buildings were also responsible for $40 \%$ of greenhouse gas emissions in the Bundang district. The greenhouse emissions of residential buildings have stabilized and reductions in energy consumption have been offset by a decrease in district heating and gas consumption (approximately $4.2 \%$ and $16.7 \%$ in 2005 and 2009 , respectively). Electricity accounted for nearly half of the total energy being consumed by residential buildings and increased by $7 \%$ in 2009 with spikes in the summer months (e.g., in mid-August, following the monsoon and typhoon seasons and between the hours of 2-4 p.m.). During the extremely cold winter months, the change of seasons and increasing number of housing units resulted in the high use of heating and air conditioning systems [10]. However, of this figure, $98.5 \%$ was attributable to apartment construction [11]. According to the Korea Power Exchange, as a consequence of space heating increasing electricity consumption and given the low and stable pricing of electricity (compared to petroleum and natural gas), Korea's period of peak electricity demand no longer occurs only in summer. 


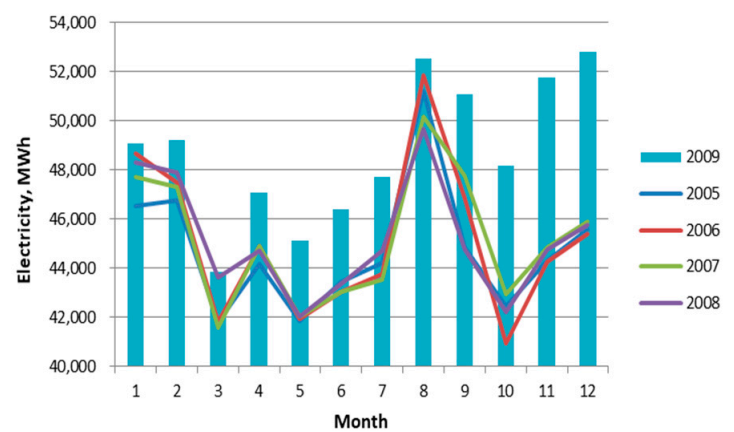

(a)

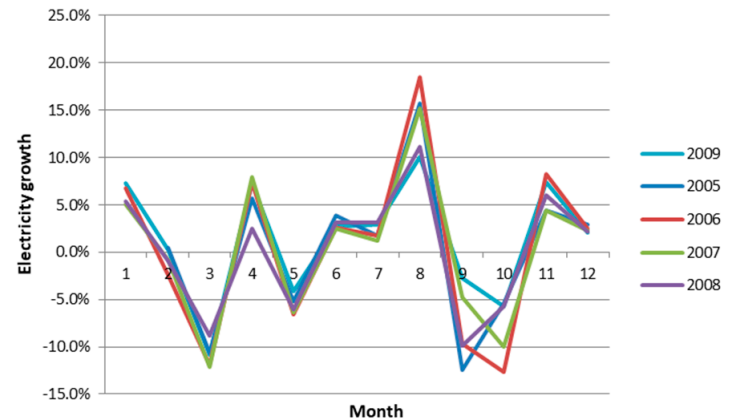

(b)

Figure 2. Monthly change: (a) electricity demand; (b) electricity growth.

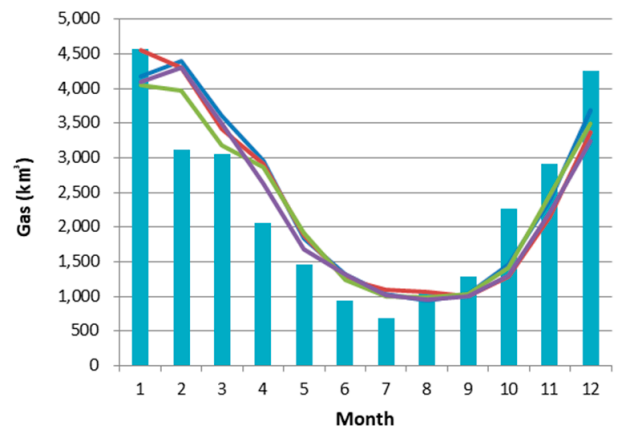

(a)

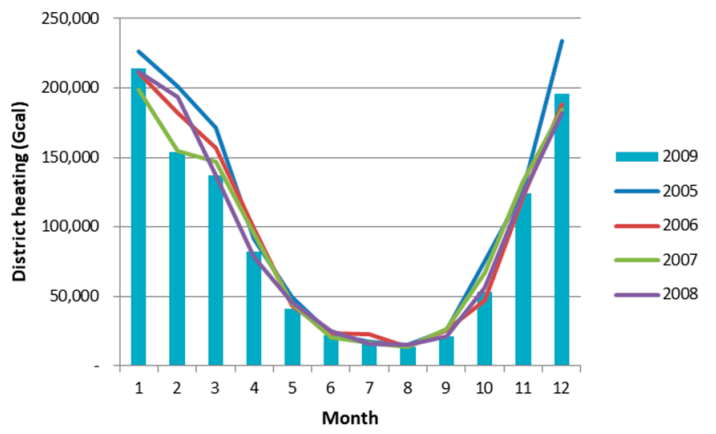

(b)

Figure 3. Monthly change: (a) gas demand; (b) district heating demand.

\section{Domestic Energy Indicators}

Analyses of the factors affecting energy consumption in domestic environments are important and should be reviewed [12]. This section identifies domestic energy indicators in relation to current laws, policies, acts, and regulations directed at energy savings and efficiencies that seek to meet carbon dioxide reduction targets.

\subsection{Household Structures and the Construction Market}

According to the Minister of Land, Infrastructure, and Transport (MOLIT), buildings over 15 years old that were designed prior to the announcement of the integrated building design criteria directed at saving energy and intensifying thermal transmittance requirement account for almost $74 \%$ of national buildings. Meanwhile, buildings over 30 years old that were designed before the implementation of the mandatory energy-saving plan submission that set regional insulation standards for building elements account for $44 \%$ of national buildings. The residential building sector (especially old, small, detached houses) uses high amounts of energy and thus requires more improvement than other sectors. In 2010, residential buildings in the Bundang district accounted for more than $86 \%$ of the total floor area, a figure somewhat higher than the national average of $72 \%$. Table 1 shows Bundang 2010 residential building statistics. Multi-family housing accounted for almost $97 \%$ of the total of residential buildings (of which $90 \%$ were apartments), a figure higher than the national average of $73 \%$ (of which $59 \%$ were apartments). The majority of residential buildings (i.e., 84\%) were constructed between 1980 and 2004 . Notably, a majority of these buildings were the result of a period of intensive building under the New Town project that ran from 1991 to 1995. The remaining residential buildings (i.e., 16\%) accounted for less than 1\% every year (except in 2003 to 2004 and 2009 to 2010, respectively, when the construction of residential buildings dramatically increased due to the Shinbundang Line (one of newest commuter railways) and economic deregulation). Over the past 30 years, small detached houses have significantly 
declined from $20.31 \%$ in 2000 to $2.99 \%$ in 2010; however, the national average still has the highest percentage (i.e., $30.64 \%$ ).

Table 1. Bundang 2010 residential building statistics.

\begin{tabular}{ccccccccccc}
\hline Building Type & $\mathbf{2 0 1 0}$ & $\mathbf{2 0 0 9}$ & $\mathbf{2 0 0 8}$ & $\mathbf{2 0 0 7}$ & $\mathbf{2 0 0 6}$ & $\mathbf{2 0 0 5}$ & $\mathbf{1 9 9 5} \mathbf{2 0 0 4}$ & $\mathbf{1 9 8 0} \mathbf{1 9 9 4}$ & Before 1979 & Total \\
\hline Detached House & 291 & 53 & 18 & 39 & 22 & 72 & 2674 & 597 & 116 & 3882 \\
Apartment & 1984 & 16,145 & 615 & 371 & 0 & 204 & 34,135 & 59,857 & 0 & 113,311 \\
Townhouse & 137 & 189 & 0 & 0 & 18 & 62 & 4894 & 2095 & 0 & 7395 \\
Multiplex House & 11 & 7 & 62 & 32 & 23 & 138 & 707 & 0 & 0 & 980 \\
House in Non-Residential Building & 3 & 3 & 5 & 6 & 6 & 6 & 75 & 18 & 3 & 125 \\
Total & 2426 & 16,397 & 700 & 448 & 69 & 482 & 42,485 & 62,567 & 119 & 125,693 \\
\hline
\end{tabular}

Figure 4 shows that the proportion of small households (i.e., single-person households, couple households, or couple households with one child) steadily by over $80 \%$ (i.e., 38,364 households) in 2000 and $42.3 \%$ (i.e., 49,152 households) in 2005 to 69,934 households in 2010 . The number of households with four and more members decreased over time and, notably, there has been a $71.9 \%$ increase in the number of people living alone over the last five years.

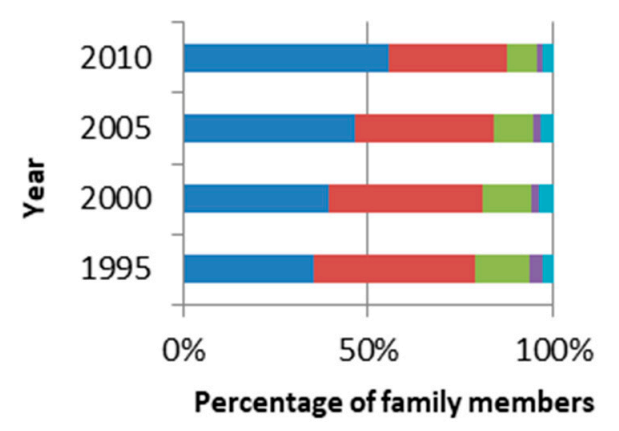

(a)

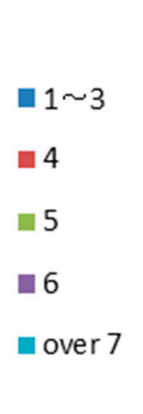

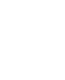

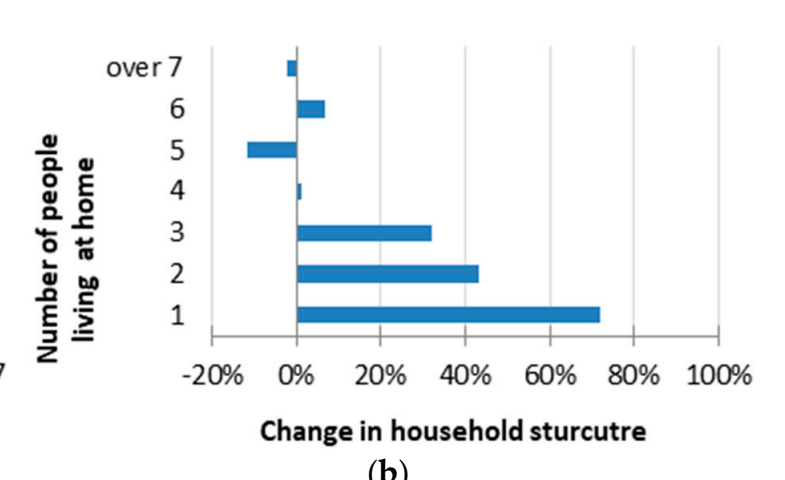

(b)

Figure 4. (a) Component ratio; (b) rate of household structure increase from 2005 to 2010.

\subsection{Climate Changes and Building Energy Consumption}

Climate change is a major factor affecting the energy consumption of residential buildings [13]. It is particularly important given the long lifespan of buildings and changing household structures. Figure 5 sets out the daily means, maximum, and minimum dry bulb temperatures and the rainfall measurements observed and recorded hourly by the Korea Meteorological Administration over the last 20 years (i.e., January 1989 to December 2008). The data shows that during the winter months (i.e., December, January, and February) and summer months (i.e., August and September) a large amount of electricity was used in Seoul.

The average temperature between 1999 and 2008 was $12.89{ }^{\circ} \mathrm{C}$. Excluding the year 2005, which had unusually severe cold weather in December, the temperatures exceeded the 30-year average temperatures of $12.5^{\circ} \mathrm{C}$. The average monthly temperatures had a variation of $27.25^{\circ} \mathrm{C}$. January was the coldest month with a mean temperature of $-1.58^{\circ} \mathrm{C}$, and August was the warmest month with a mean temperature of $25.67^{\circ} \mathrm{C}$. The range of diurnal average temperature was $7.66^{\circ} \mathrm{C}$. A slight change over the years can be seen in Figure 5. For the last five years of the study period, temperatures decreased slightly in winter (especially in January) and temperatures have been generally mild with a wide range of temperature change each year. Since 2008, the minimum temperature between December and February dropped by $-7.4{ }^{\circ} \mathrm{C},-10.5^{\circ} \mathrm{C}$ and $-6{ }^{\circ} \mathrm{C}$, respectively, breaking the record for the lowest temperatures. This drop in temperature is one of the major factors affecting winter peak power demand for space heating $[13,14]$ (see Figure 6). 


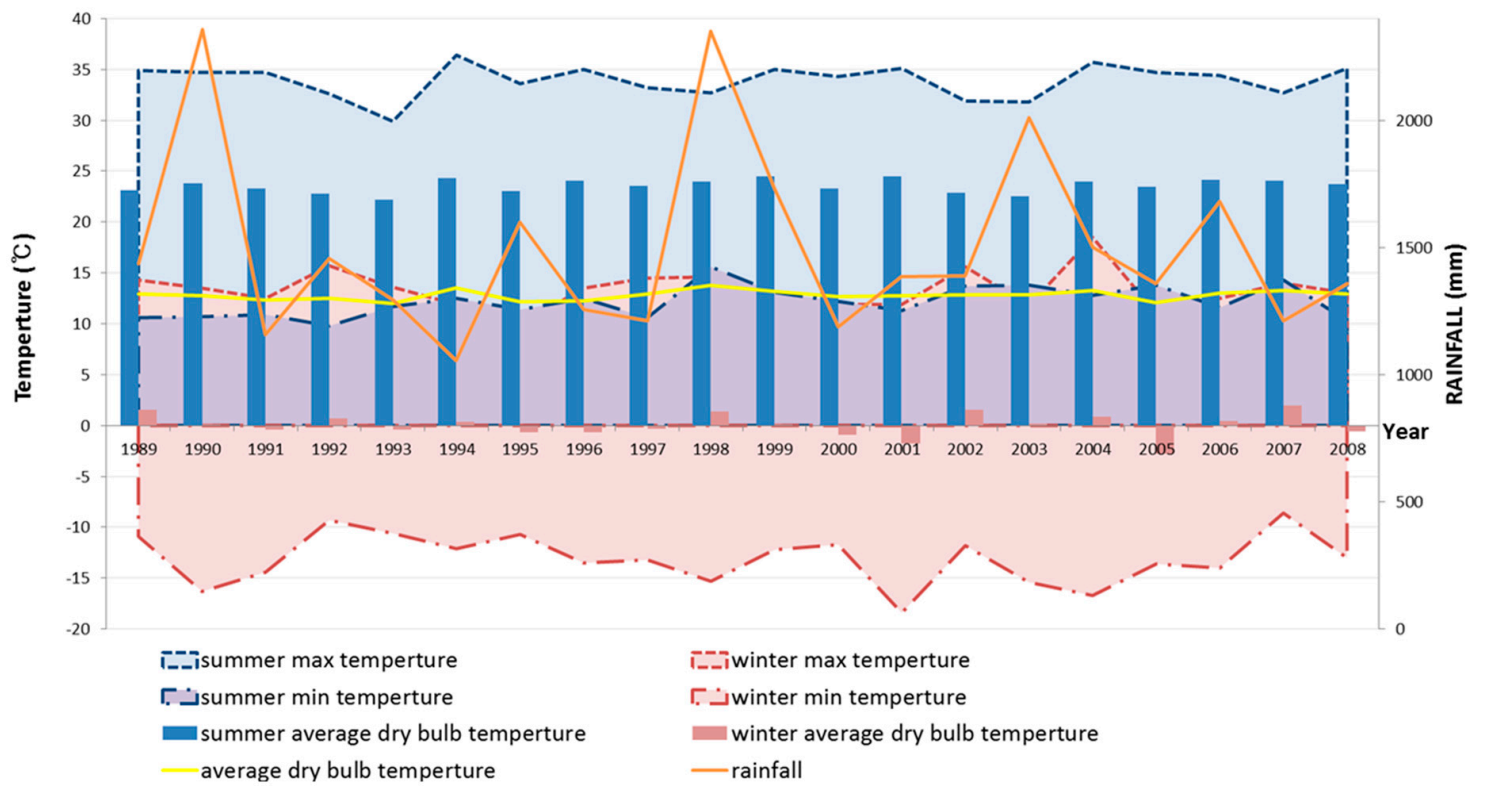

Figure 5. Dry bulb temperatures and rainfall measurements from 1989 to 2008.

The majority of annual precipitation occurred in summer (i.e., June to August) when there was heavy rainfall of $400 \mathrm{~mm}$ to $1300 \mathrm{~mm}$. The amount of precipitation from July to August (i.e., $60 \%$ ) should be compared to the amount of precipitation from December to February over the last 20 years (i.e., under 5\%). Recently, the amount of monthly and annual rainfall has gradually decreased, as dry monsoon seasons have decreased the frequency of daily rainfall over $50 \mathrm{~mm}$. In August, the number of rainy days has changed little over the last two decades (i.e., 1994 to 2003 and 2004 to 2013); however, there has been a decrease of $36 \%$ and an increase in very short-term torrential rains. Longer, hot, and humid summer days substantially increased energy demands, as residents sought comfortable indoor environments [10].

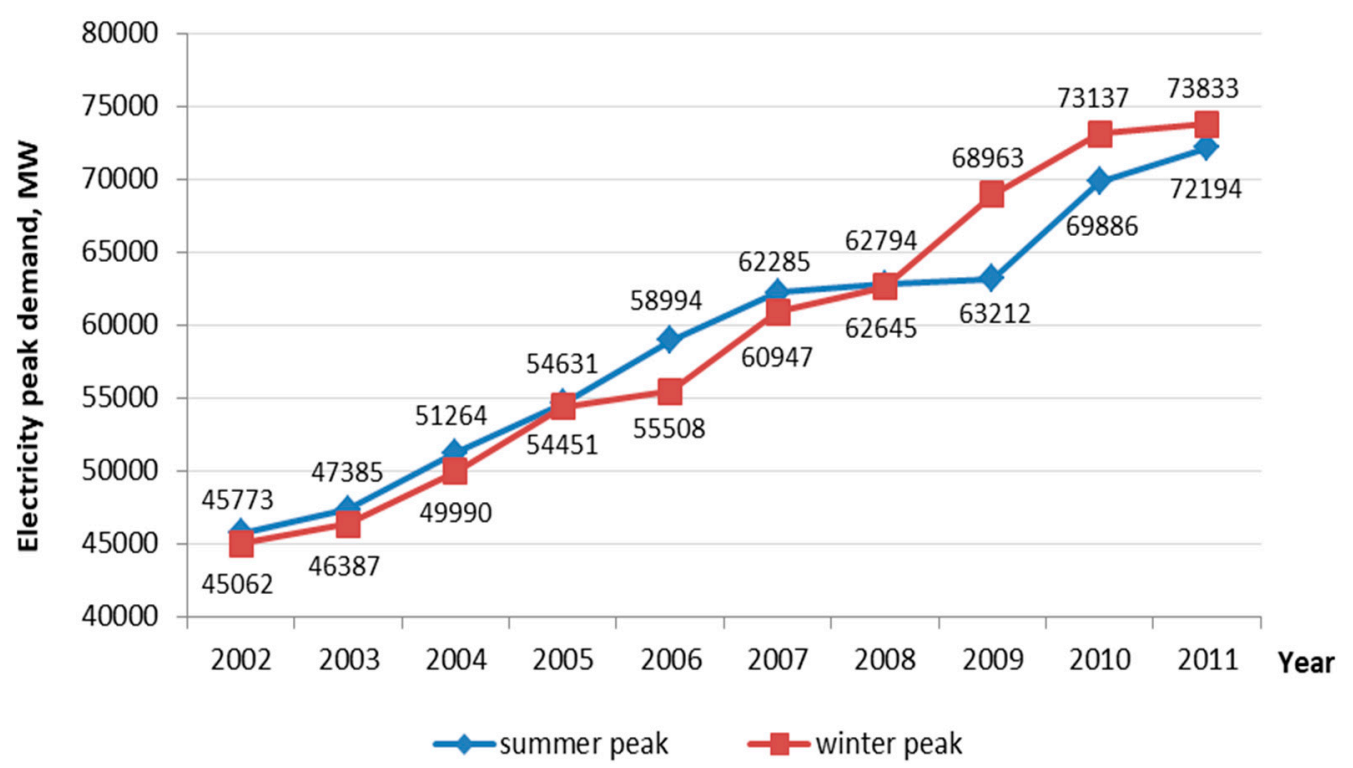

Figure 6. Annual summer and winter peak demands in Korea (source: Ministry of Trade, Industry, and Energy. The Sixth Basic Plan for Long-term Electricity Supply and Demand (2013-2027)). 


\subsection{Building Laws, Policies, Acts, and Regulations}

To address the effects of climate change and resource shortages, the MOLIT in collaboration with the Minister of Trade, Industry, and Energy (MOTIE) and the Minister of Environment (ME) implemented and continues to strengthen laws, policies, acts, and regulations related to the energy use and carbon dioxide emission of buildings. However, due to a lack of coordination within and between departments, these laws, policies, acts, and regulations continue to operate ineffectively and have failed to produce many tangible results. In recent years, the central government has engaged in various efforts such as restructuring government departments and subordinate agencies and arranging conferences, seminars, and workshops to address these issues.

The Building Act failed to address future energy demand changes and consumption patterns. Thus, the Green Building Creation Support Act (2013) was enacted to provide a detailed master plan directing low carbon green growth. Some building owners have voluntarily participated in building certification programs (e.g., the Green Standard for Energy and Environmental Design (G-SEED)) that were the product of a number of merged systems (i.e., the Low Carbon Green Building Certification system based on the Building Act, and the Housing Performance Rating system based on the Housing Act, as well as the Energy Efficiency Rating Systems). These programs sought to reduce council taxes and environmental improvement charges under the Act. A number of programs have been launched for apartment building and, recently, these programs have been expanded to different types of buildings in both the public and private sectors and are now mandatory in relation to publicly owned or constructed building over $3000 \mathrm{~m}^{2}$. The Act also continues to strengthen the Energy Saving Design Criteria, especially in relation to building materials and control systems for energy efficiency (i.e., since early 2000, to obtain a building permit, buildings under the Building Act have to meet mandatory requirements and reach at least 65 points on the Environmental Performance Index (EPI)) [15].

The government implemented a number of policies and regulations related to renewable energy supply and demand-side management for maximizing energy efficiency, including the Energy Act, the Rational Energy Utilization Act, and the Act on the Promotion of the Development, Use, and Diffusion of New and Renewable Energy. Further, the government prepared Energy Use Plans for small- and large-scale urban development projects that included efficiency certifications and rating systems with settings for the efficient management of materials and equipment, the use of standby power and high efficiency appliances, Direct Load Control (DLC), and cold thermal energy storage support for electricity load management. There are several financial incentives for energy efficiency provided by the authorities. Seoul, the capital of Korea, has performed a campaign recognizing households that reduce energy consumption, and provides energy consulting services as well as awards for the accomplishment of reduced emissions. They also distribute "eco mileage," which is increased according to the rate of the reduction in energy consumption in households. With accumulated mileage, households can purchase eco-friendly products. The Kyunggi-do, one of the state governments, conducts an "energy save back", which returns the profits of energy savings to the building owners. Additionally, the government encourages companies to save power between 2 p.m. and 4 p.m., and staff to take their summer holidays in periods of peak demand. Temperatures have been regulated (e.g., by limiting heating temperatures to below $20^{\circ} \mathrm{C}$ and cooling temperatures to over $26^{\circ} \mathrm{C}$ in public buildings and buildings consuming over 2000 tons of oil equivalent per annum), and stable supply and demand plans such as community energy, Combined Heat and Power (CHP), smart grid, and Renewable Portfolio Standards (RPS) systems have been implemented.

Despite these efforts, Korea has been experiencing electricity shortage problems, leading to blackouts. Consequently, the country experienced power reserve dips of below $10 \%$ for 9 days in 2009, 46 days in 2010, 51 days in 2011, and 129 days in 2012 due to increasing usage per units of land area (Korea Power Exchange). Further, in recent years, peak electricity demand has also been created during the winter months (see Figure 6) [16]. 


\section{Discussion and Conclusions}

Many researchers have proposed strategies contributing to building energy savings. Governments have made efforts to develop administrative and financial support for energy savings and to improve policies directed at achieving energy-saving targets. We analyzed the factors affecting energy consumption through a case study of the Bundang district. The total energy consumption (including electricity, gas, and district heating) was analyzed in relation to building types in the Bundang district, and it was found that residential buildings account for approximately $37 \%$ of the total energy consumption of buildings. Further, approximately $77 \%$ of energy consumed in residential buildings was for general heating, water heating, and cooking (heating load), and the remaining $23 \%$ was used for air conditioning, electronics, and lighting (electricity load). Although the greenhouse emissions of residential buildings have stabilized as a consequence of a decrease in district heating and gas consumption, the change of seasons as well as the increasing number of housing units has resulted in a high use of heating and air conditioning systems; thus, Korea's period of peak electricity demand no longer occurs only in specific seasons. We also reviewed domestic energy indicators in terms of household structures, climate change, and building laws, policies, and regulation directed at energy savings, and efficiencies in carbon dioxide reduction. It was found that the proportion of small households steadily increased, whereas the number of households with four or more members decreased more gradually over time. In addition, despite the government's efforts in terms of building laws, policies, and regulations, Korea has experienced electricity shortage problems leading to blackouts, and, consequently, has experienced power reserve dips of below $10 \%$ (most recently for 129 days). Several issues that researchers and governments need to address in terms of the reduction of energy demand have been highlighted based on the results of this research. Three crucial issues, specifically related to current policies, acts, and regulations, are described below.

\subsection{Improving Energy Performance in Existing Residential Buildings}

The government's policies currently focus on regulating new buildings with more than $3000 \mathrm{~m}^{2}$ total floor area and buildings owned and occupied by public institutions (e.g., such buildings must obtain certain grades for building energy certification and rating under the Green Building Creation Support Act). National regulations related to energy saving and efficiency do not refer to existing buildings, as the majority of these building were constructed during the growth period of building energy policy and new construction activity has substantially declined in recent years (see the analysis in Section 3.1). Further, residential buildings have had a small role in reducing electric energy consumption. The reasons for this can be divided into political and social aspects. In relation to the political aspect, compared to other types of building, there has been a lack of mandatory restrictions for residential buildings, especially for existing housing that is over $3000 \mathrm{~m}^{2}$ (except multi-family residential housing) or less than $500 \mathrm{~m}^{2}$. Indeed, the government has failed to amend existing laws, policies, acts, and regulations in relation to the energy efficiency of substantial housing less than $500 \mathrm{~m}^{2}$ built nearly 30 years ago. In relation to the social aspect, the proportion of households using more than $351 \mathrm{~kW} \cdot \mathrm{h}$ per month continues to increase due to changes in household structure (i.e., as more people live in smaller households) (see the analysis in Section 3.1). According to a report published by the Seoul Institute, single-person households have the highest electric energy consumption per capita and their consumption is almost 2.5 times larger than households of four or more people. Increased energy consumption has been attributed to the introduction of new electrical appliances related to wellbeing and convenience, increased incomes, and the use of large-capacity systems such as air conditioning, dehumidifiers, and air cleaners. Thus, the government needs to provide systematic, middle, and long-term guidelines that reflect social changes for development, the implementation of new technologies, and encourage people to voluntarily join in energy saving. 


\subsection{Strengthening Building Design Criteria for Climate Change Effects and Adaptation}

Current policies for new buildings fail to address extreme climate change and its effects. The annual temperatures for late 2000 were the coldest temperatures recorded in Korea; severe heat waves have also been occurring more frequently for long periods; and droughts are occurring due to a decline in the frequency of heavy rainfall. The Building Design Criteria for Energy Saving (BDCES) created an assessment for energy efficiency across four categories: design/construction basics, mechanical equipment, electrical equipment, and renewable energy. Through the energy-focused refurbishment of residential buildings, Ortiz et al. $[17,18]$ argued for the strength of passive strategies adopted in building designs relating to natural ventilation and lighting, and reducing the demand for heating, which is beneficial from an economic and thermal-comfort point of view. They showed that passive strategies affording energy efficiency provide comfortable conditions for the warm period without the use of cooling systems and thereby provide economic benefits as well. Oliveira et al. [19] also emphasized that the choice between different materials and construction systems can influence the energy performance and the cost of building through a case study of Portuguese projects. However, improving the energy efficiency of building fabrics will not occur if tighter controls for building designs are not implemented. Compared to other categories, the 'design/construction basics' category to meet BDCES has generated little interest because the effects of energy saving is relatively insignificant economically, and thus limited technology development has been undertaken. For example, Korea's technique of sealing windows with frames is particularly vulnerable to heat wave lags. The use of large amounts of glass in new buildings is an important issue to be considered in relation to climate change, because windows may account for 20 to $45 \%$ of overall heating loss; however, this issue has not been appropriately considered by current policies. The BDCES are continually being strengthened by energy efficiency regulations, but they do not adequately address problems such as improper thermal insulation and structural heat loss through external wall insulation systems. For example, most multi-family housings in typical residential building use external wall insulation systems that were designed without considering regional climates and frequently reach critically poor insulation levels due to the thermal bridges being created by placing balconies off rooms and the use of inadequate materials (without vapor barriers to prevent moisture penetration). In addition, current building design criteria use Central European temperatures for the U-value criteria and not Korean temperatures. Building design criteria should consider Korea's circumstances and be strengthened for climate change effects and adaptation.

\subsection{Preparing a Concrete Framework to Revitalize Energy-Saving Policies}

MOLIT has recently established some organizations (e.g., the Green Building Center and the Green Remodeling Creation Center) in government agencies or public institutions to implement policies, acts, and regulations. However, due to limited budgets, ineffective budget allocation, and policy overlap, these organizations have not achieved satisfying results via private company participation or local government support. For example, MOLIT commenced a remodeling project for buildings owned and occupied by public institutions to vitalize 'green' buildings. However, local governments did not extended this project to private buildings for reasons such as a shortage of building energy specialists, insufficient information for detailed plans, and a stationary budget. Further, current rating systems that seek to evaluate performances have not achieved energy-saving effects; for example, the G-SEED assessment uses qualitative methods and the Energy Efficiency Rating System uses questions related to environmental and technological changes. Thus, more careful comparisons and analyses of rating systems are needed to identify and develop the effectiveness of the rating systems. Garrido et al. [20] raised an important problem in terms of legislation by estimating the greenhouse gas emissions, potential energy savings, and economic benefits of residential buildings in Catalonia through a comparative study of national and regional efficiency scenarios. They found that the regional regulations were less restrictive than the national ones, so the former were not justified. For example, the national requirements that defined climate zones, applying more restrictive criteria 
for using glass, were more effective than regional ones. It is desirable for regulations to include the most restrictive national requirements to improve energy savings and economic efficiency. A relevant evaluation algorism for new technologies also needs to be developed to ensure the rapid spread of new technologies, and promote energy conservation. Rating systems should also be regularly upgraded to reflect new technologies in energy saving. Further, skilled labor should be used to evaluate the energy performances of buildings, and to continue the training programs provided, as it is difficult to find high-quality instructors given the operating budget. Consequently, to achieve energy saving targets, the government should prepare a concrete framework that establishes a properly funded specialized organization, operate a training program aimed at developing skilled manpower, and set design criteria that reflects domestic circumstances. Certain energy-saving programs have been launched by the Korean government as strategies for supporting building owners financially. These include local tax reductions, loan support-such as building retrofit project (BRP) loans and renewable energy loans-and regulation relaxation. However, such energy-saving programs have not delivered the expected results, as the financial benefits from these programs are not significant, and the continuous, integrated operation of specialized organizations, as well as cooperation between various government departments, has not performed properly.

The role of the governments is indispensable for the reduction of energy consumption and greenhouse gas emissions in the building sector. The direction of long-term research and development investment has recently shifted its focus from building envelope technology to automation and energy management systems aimed at improving energy efficiency. The government created energy and greenhouse gas information systems based on monthly consumptions of electricity, district heating, and gas in 6.9 million units, and offered administrative and financial support services to those developing energy management plans (although this did not produce the expected results because of a shortage of skilled manpower, as mentioned above, in relation to increasing demand). Further, short-term research and development has been allocated nearly $15 \%$ of the long-term research and development budget; however, this research is only directed at small and medium-sized companies. Korea's current policies and direction for the energy demand reduction will not lead to commercial applications due to technological and budget limitations, thus they should be revised in consideration of the issues highlighted in this research to establish an environment in which major companies are able to actively participate and competitive medium-sized companies be nurtured. Such participation will ease the government's burden and provide effective financial support. Further, the government should seek to strengthen the role of organizations and local governments to ensure they operate various programs in the short term as well as in the long term.

Acknowledgments: This work was supported by the National Research Foundation of Korea Grant funded by the Korean government (NRF-2016R1A2B4007752).

Author Contributions: Kwon Sook Park analyzed the data; Kwon Sook Park and Mi Jeong Kim wrote the paper.

Conflicts of Interest: The authors declare no conflict of interest.

\section{References}

1. Chung, U.; Cho, J.; Yun, J.I. Urbanization effect on the observed change in mean monthly temperature between 1951-1980 and 1971-2000 in Korea. Clim. Chang. 2004, 66, 127-136. [CrossRef]

2. International Energy Agency (IEA). Energy and Climate Change; World Energy Outlook Special Report; International Energy Agency: Paris, France, 2015.

3. Johnston, D.; Lowe, R.; Bell, M. An exploration of the technical feasibility of achieving $\mathrm{CO}_{2}$ emission reductions in excess of $60 \%$ within the UK housing stock by the year 2050. Energy Policy 2005, 33, 1643-1659. [CrossRef]

4. Minister of Land, Infrastructure and Transport (MOLIT). The 1st Green Building Master Plan; Minister of Land, Infrastructure and Transport: Sejong-si, Korea, 2014.

5. Minister of Environment (ME). National Greenhouse Gas Emissions Reduction Road Map 2020; Minister of Environment: Sejong-si, Korea, 2014. 
6. Jeong, Y.D.; Yu, M.G.; Nam, Y. Feasibility Study of a Heating, Cooling and Domestic Hot Water System Combining a Photovoltaic-Thermal System and a Ground Source Heat Pump. Energies 2017, 10, 1243. [CrossRef]

7. Oncioiu, I.; Petrescu, A.G.; Grecu, E.; Petrescu, M. Optimizing the Renewable Energy Potential: Myth or Future Trend in Romania. Energies 2017, 10, 759. [CrossRef]

8. Goldsworthy, M. Towards a Residential Air-Conditioner Usage Model for Australia. Energies 2017, $10,1256$. [CrossRef]

9. Coakley, D.; Raftery, P.; Keane, M. A Review of Methods to Match Building Energy Simulation Models to Measured Data. Renew. Sustain. Energy Rev. 2014, 37, 123-141. [CrossRef]

10. Intrgovernmental Panel on Climate Change (IPCC). Climate Change 2014: Synthesis Report, Contribution of Working Group I, II and III to the Fifth Assessment Report; Intrgovernmental Panel on Climate Change: Geneva, Switzerland, 2015.

11. Minister of Land, Infrastructure and Transport (MOLIT). Electric Architectural Administration Information System; Minister of Land, Infrastructure and Transport: Sejong-si, Korea, 2009.

12. Pérez-Lombard, L.; Ortiz, J.; Pout, C. A review on building energy consumption information. Energy Build. 2008, 40, 394-398. [CrossRef]

13. Wang, X.; Chen, D.; Ren, Z. Assessment of climate change impact on residential building heating and cooling energy requirement in Australia. Build. Environ. 2010, 45, 1663-1682. [CrossRef]

14. Frank, T. Climate change impacts on building heating and cooling energy demand in Switzerland. Energy Build. 2005, 37, 1175-1185. [CrossRef]

15. Park, K.S.; Kim, S. Building codes and energy efficiency policies with the change of the time in Korea. In Proceedings of the 13th APRU Doctoral Student Conference, Jakarta, Indonesia, 18-24 August 2014.

16. Minister of land, Infrastructure and Transport (MOLIT). The 6th Basic Plan for Long-term Electricity Supply and Demand; Minister of land, Infrastructure and Transport: Sejong-si, Korea, 2013.

17. Ortiz, J.; Fonseca, A.; Salom, J.; Garrido, N.; Fonseca, P.; Russo, V. Comfort and economic criteria for selecting passive measures for the energy refurbishment of residential buildings in Catalonia. Energy Build. 2016, 110, 195-210. [CrossRef]

18. Ortiz, J.; Casas, A.F.; Salom, J.; Soriano, N.G.; Casas, P.F. Cost-effective analysis for selecting energy efficiency measures for refurbishment of residential buildings in Catalonia. Energy Build. 2016, 128, 442-457. [CrossRef]

19. Oliveira, F.; Mendonça, P.; Couto, J.P.; Camões, A.; Silva, E. Comparative environmental and economic analysis of south european building constructive systems. WSEAS Trans. Environ. Dev. 2014, 10, 509-528.

20. Garrido-Soriano, N.; Rosas-Casals, M.; Ivancic, A.; Castilloa, M.; Álvarez-del, D. Potential energy savings and economic impact of residential buildings under national and regional efficiency scenarios. A Catalan case study. Energy Build. 2012, 49, 119-125. [CrossRef] 